\title{
Some physical properties of kariya (Hildegardia barteri) nut/ kernel relevant to the design of its processing equipment
}

\author{
Ubong Edet Assian * and Akindele Folarin Alonge \\ Department of Agricultural and Food Engineering, Faculty of Engineering, University of Uyo, Uyo, P.M.B. 1017, Akwa \\ Ibom State, Nigeria.
}

Global Journal of Engineering and Technology Advances, 2021, 07(02), 083-090

Publication history: Received on 12 April 2021; revised on 20 May 2021; accepted on 22 May 2021

Article DOI: https://doi.org/10.30574/gjeta.2021.7.2.0071

\begin{abstract}
Kariya kernel is very rich in essential fats, oils and other valuable nutrients which may find applications in many food formulations. To harness these nutrients, processing equipment and machines are to be used. In order to effectively design these machines, the values of some physical properties of kariya nut and kernel are needed. In this study, some physical properties of the kariya nut and kernel were investigated. Results showed that mean major diameter, intermediate diameter, minor diameter and unit mass obtained at the nut moisture content of $19.83 \pm 3.71$ (w.b.) were $14.16 \pm 0.79 \mathrm{~mm}, 10.17 \pm 0.36 \mathrm{~mm}, 9.78 \pm 0.28 \mathrm{~mm}$ and $0.503 \pm 0.05 \mathrm{~g}$, respectively while the corresponding values obtained at the kernel moisture content of $8.89 \pm 2.22 \%$ (w.b.) were $9.07 \pm 0.72 \mathrm{~mm}, 7.32 \pm 0.49 \mathrm{~mm}, 7.08 \pm 0.41 \mathrm{~mm}$ and $0.328 \pm 0.03 \mathrm{~g}$, respectively. The values of calculated geometric mean diameter were $11.20 \pm 0.33 \mathrm{~mm}$ and $7.77 \pm$ $0.36 \mathrm{~mm}$, for the kariya nut and kernel, respectively. The skewness value of the sample distribution of 0.08 and -0.24 were recorded for the kariya nut and kernel, respectively. The sphericity, surface area, volume, density, bulk density and porosity were $79.27 \pm 3.07 \%, 394.75 \pm 23.13 \mathrm{~mm}^{2}, 738.37 \pm 64.96 \mathrm{~mm}^{3}, 681.1 \pm 20 \mathrm{~kg} / \mathrm{m}^{3}, 440.24 \pm 0.04 \mathrm{~kg} / \mathrm{m}^{3}$ and $36.65 \pm 0.74 \%$; and $85.97 \pm 5.27 \%, 189.85 \pm 17.34 \mathrm{~mm}^{2}, 246.71 \pm 33.60 \mathrm{~mm}^{3}, 1342.1 \pm 136.23 \mathrm{~kg} / \mathrm{m}^{3}, 773.06 \pm$ $0.06 \mathrm{~kg} / \mathrm{m}^{3}$ and $42.28 \pm 4.10 \%$ for the kariya nut and kernel respectively.
\end{abstract}

Keywords: Physical properties; Kariya nut/ kernel; Design; Processing equipment

\section{Introduction}

Kariya tree (Hildegardia barteri) is cultivated majorly for its ornamental purposes. Its origin is traced from West Africa. It produces flowers during the dry season. Flowers are borne on branches which have no leaves and matured into monoseeded pods [1]. Each pod is about $50 \mathrm{~mm}$ in length, bearing a peanut-like seed. The ripen pods drop and dispose as soon as they are dried. The kernels are always eaten raw or roasted like groundnuts in some parts of West Africa. They are used as ingredients in some local food recipes [2]. Kernel has proximate composition of $17.5 \%$ crude protein, $37.5 \%$ crude fat, $2.8 \%$ ash and $6.5 \%$ crude fibre. The crude protein content of kariya kernel competes reasonably with $19.8 \%$ for both sunflower and pistachio seeds, $15.6 \%$ for walnut kernel; whereas, it is less than $20 \%$ for mustard, $20.3 \%$ for linseed, $20.8 \%$ for almond seeds and $21.2 \%$ for cashew nuts [3]. This protein content can be explored in many food applications. The crude fat content of kariya kernel comprises of $77 \%$ of saturated and $23 \%$ of unsaturated fatty acids. Almost the same composition is found in palm kernel oil with $82 \%$ saturated and $18 \%$ unsaturated fatty acids [4]. These oils are practically stable and will turn into solid at room temperature. Its fat content has approximately the same amount of linolenic, palmitic, myristic and stearic acid, which is not common among oil seeds. Traditional processing of kariya nut involves sun drying of the pods, manual dehulling of the leaf-like coverage and cracking of the nut using hands or stones to obtain kernels and shell fragments (Figure 1). However, the operations involved in traditional

\footnotetext{
${ }^{*}$ Corresponding author: Ubong Edet Assian

Department of Agricultural and Food Engineering, Faculty of Engineering,University of Uyo, Uyo, P.M.B. 1017, Akwa Ibom State, Nigeria.
}

Copyright (c) 2021 Author(s) retain the copyright of this article. This article is published under the terms of the Creative Commons Attribution Liscense 4.0. 
methods of processing are yet to be mechanized which could reduce drudgery and create opportunity for large scale operation [5].
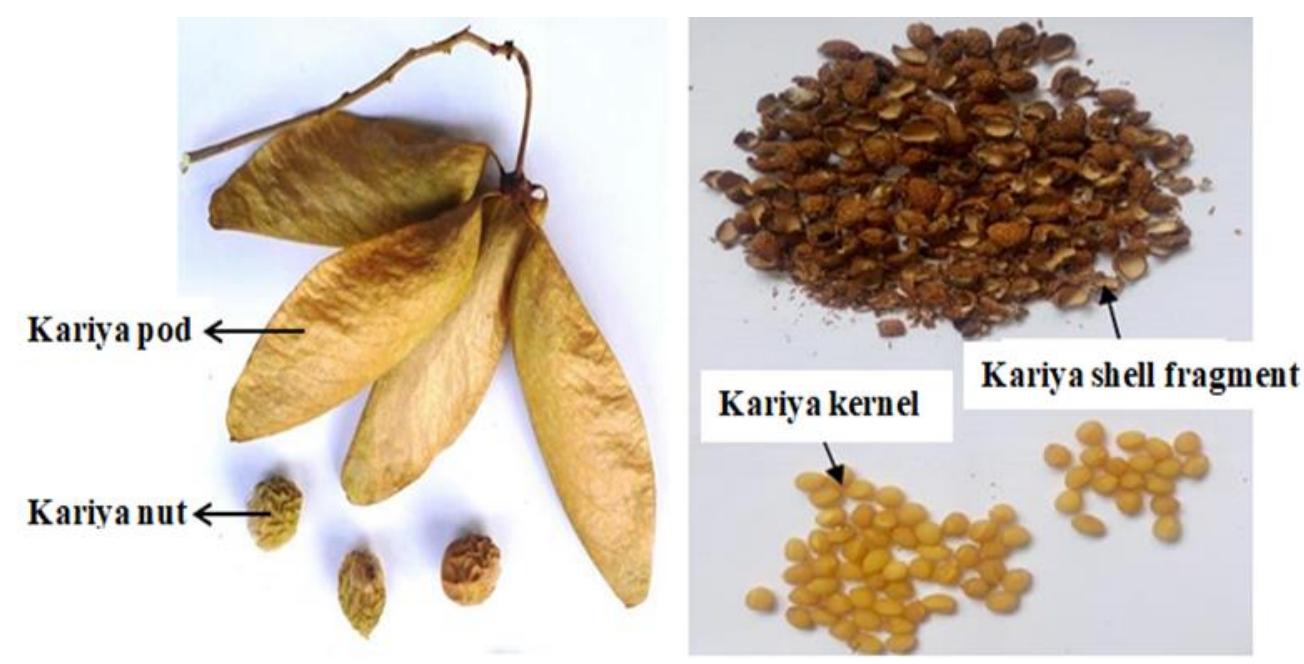

Figure 1 Kariya pod, nut, kernel and shell fragment

Many researchers have carried works on some physical and engineering properties of seeds, nuts, grains, tuber crops, and vegetables in order to provide useful information likely to be employed in the design of crop and food processing equipment $[6,7,8,9]$. Some researches were studied with respect to variation of nut, seeds and grains moisture content $[8,10,11]$, while others were carried out at initial moisture content $[13,14]$. These physical and engineering properties include geometric mean diameter (which is a function of major diameter, minor diameter and intermediate diameter), sphericity, static and dynamic angles of repose, coefficient of friction, specific gravity, unit weight/mass, volume, surface area, porosity, aspect ratio, true, solid and bulk densities, bio yield, stiffness, elastic deformation, hardness, shear resistance, compressibility, tensile strength, rupture, toughness, thermal conductivity, thermal diffusivity, specific heat capacity, etc $[15,16,17,18]$. In order to tap these essential nutrients found in kariya kernels for commercial purpose, efficient processing equipment and vessels are needed. But there is scanty information on the physical and engineering properties of kariya nut/ kernel for rational design and fabrication of these machines. Therefore, there was need to provide these pieces of information. Hence, the objective of this study was to determine some physical properties of kariya nut and kernel such as size, shape, geometric mean diameter, sphericity, surface area, volume, unit mass, solid density, bulk density, and porosity with respect to their initial moisture content, so that Food scientists and processors could also exploit these data in their various disciplines for further researches and processing.

\section{Material and methods}

About 800 dried kariya pods were sourced from University of Uyo Town Campus, Uyo, Nigeria. The bulk pods were winnowed to remove foreign materials. Exactly 100 pods were picked at random and dehulled to obtain the nuts. After the first phase of the experiment with the nuts, the nuts were manually cracked and cleaned to obtain kernels for the second phase. The initial moisture content of the nuts and kernels (20 samples each) was determined using gravimetric method as described by ASABE [19], Antia et al. [20], Alonge and Etim [21] and Alonge et al. [11]. The nut and kernel masses were measured using digital weighing balance, while their axial dimensions (major, minor and intermediate diameters) were taken using digital vernier calipers of $0.01 \mathrm{~mm}$ calibration. The dimensions were used to determine some physical properties of kariya nuts and kernels using Equations 1 to 9. For the purpose of assessing the nut and kernel size distribution, they were classified each, based on GMD, into three size ranges: small $(10.5 \mathrm{~mm} \leq \mathrm{GMD}<11.0$ $\mathrm{mm})$, medium $(11.0 \mathrm{~mm} \leq \mathrm{GMD}<11.5 \mathrm{~mm})$, large size ranges $(11.5 \mathrm{~mm} \leq \mathrm{GMD}<12.0 \mathrm{~mm})$; and small $(6.0 \mathrm{~mm} \leq \mathrm{GMD}$ $<7.0 \mathrm{~mm})$, medium $(7.0 \mathrm{~mm} \leq \mathrm{GMD}<8.0 \mathrm{~mm})$, large size ranges $(8.0 \mathrm{~mm} \leq \mathrm{GMD}<9.0 \mathrm{~mm})$ for the nuts and kernels, respectively. Their mean and standard deviation of each parameter were calculated through the aid of Data Acquisition Template powered by Microsoft Excel ${ }^{\mathrm{TM}}$. Their skewness values were also determined. The experiment was conducted in three replicates. 


\subsection{Determination of Some Physical Properties Kariya Nut and Kernels}

\subsubsection{Nut Moisture Content (MC) Determination}

The initial moisture content was found using Equation 2.1.

$\% \mathrm{MC}_{\mathrm{wb}}=\frac{\mathrm{M}_{\mathrm{i}}-\mathrm{M}_{\mathrm{f}}}{\mathrm{M}_{\mathrm{i}}} \times 100 \%$

where $\% \mathrm{MC}_{\mathrm{wb}}=$ percent moisture content wet basis, $\mathrm{M}_{\mathrm{i}}=$ initial mass of nut or kernel $(\mathrm{g})$ and $\mathrm{M}_{\mathrm{f}}=$ mass of nut or kernel at bone dry condition (g).

\subsubsection{Nut and Kernel Size, Sphericity and Shape}

Nut or kernel geometric mean diameter, as function of the axial dimensions, according to Irtwange and Igbeka [22] was calculated thus:

$\operatorname{GMD}=\left(\mathrm{d}_{1} \times \mathrm{d}_{2} \times \mathrm{d}_{3}\right)^{1 / 3}$

where GMD = nut or kernel geometric mean diameter $(\mathrm{mm}), \mathrm{d}_{1}=$ nut or kernel minor diameter $(\mathrm{mm}), \mathrm{d}_{2}=$ nut or kernel intermediate diameter $(\mathrm{mm}), \mathrm{d}_{3}=$ nut or kernel major diameter $(\mathrm{mm})$.

Skewness of the sample size distribution was calculated using Equation 2.3:

Skewness $(Đ)=3 \times\left(\frac{\text { Mean-Median }}{\text { Standard deviation }}\right)$

The sphericity of the nut or kernel was determined by using the relationship [22]:

Sphericity $(\psi)=\frac{\text { GMD }}{\mathrm{d}_{3}} \times 100 \%$

When the sphericity of a grain/seed is $\geq 0.6$ (i.e. $60 \%$ ), the shape of such a seed is regarded as a sphere [13,23].

\subsubsection{Nut or Kernel Surface Area}

Based on this study, the shape of the kariya nut and kernel are described as a sphere; hence, the nut or kernel surface area was calculated using Equation $2.5[15,23]$.

$\mathrm{S}_{\mathrm{a}}=\pi \times(\mathrm{GMD})^{2}$

where $\mathrm{S}_{\mathrm{a}}=$ nut surface area $\left(\mathrm{mm}^{2}\right)$

\subsubsection{Nut or Kernel Volume}

Nut or kernel volume was found using Equation 2.6 [15].

$\mathrm{V}_{n / k}=\frac{\pi(\mathrm{GMD})^{3}}{6}$

where $\mathrm{V}_{n / k}=$ nut or kernel volume $\left(\mathrm{mm}^{3}\right)$ and $\pi$ (pie) $=3.142$

\subsubsection{Nut or Kernel Unit Mass}

The nuts and kernels were weighed using electronic weighing balance.

\subsubsection{Nut or Kernel Density}

The density of the nut or kernel was calculated by dividing individual sample mass by its corresponding volume [15].

$\rho_{\mathrm{n} / \mathrm{k}}=\frac{\mathrm{M}_{n / k}}{\mathrm{~V}_{\mathrm{n} / \mathrm{k}}}$ 
where $\rho_{\mathrm{n} / \mathrm{k}}=$ nut or kernel density $\left(\mathrm{g} / \mathrm{mm}^{3}\right), \mathrm{M}_{n / k}=$ nut or kernel mass $(\mathrm{g})$ and $\mathrm{V}_{\mathrm{n} / \mathrm{k}}=$ nut or kernel volume $\left(\mathrm{mm}^{3}\right)$.

\subsubsection{Nut or Kernel Bulk Density}

Bulk density is simply the density of a material when stacked in a container. It was determined as described by Rao et al. [15]:

$\rho_{\mathrm{b}}=\frac{\mathrm{M}_{\mathrm{cnk}}-\mathrm{M}_{\mathrm{c}}}{\mathrm{V}_{\mathrm{c}}}$

where $\rho_{b}=$ nuts or kernel bulk density $(\mathrm{g} / \mathrm{ml}), M_{c}=$ mass of empty container $(\mathrm{g}), \mathrm{M}_{\mathrm{cnk}}=$ mass of container plus nuts or kernels $(\mathrm{g}), \mathrm{V}_{\mathrm{c}}=$ volume of empty container $\left(\mathrm{mm}^{3}\right)$

\subsubsection{Porosity}

Based on the relationship given by Mohsenin [24], the porosity of the nut or kernel was calculated thus:

$\mathrm{P}_{\mathrm{n} / \mathrm{k}}=\left(1-\left[\frac{\rho_{\mathrm{b}}}{\rho_{\mathrm{n} / \mathrm{k}}}\right]\right) \times 100 \%$

where $\mathrm{P}_{\mathrm{n} / \mathrm{k}}=$ nuts or kernel porosity $(\%)$

\section{Results and discussion}

The results of the findings are presented in Table 1 and Figure 2.

Table 1 Some physical properties of kariya (Hildegardia barteri) nut and kernel at $19.83 \%$ and $8.89 \%$ moisture content (w.b.) respectively.

\begin{tabular}{|l|l|l|l|}
\hline Properties & Total No. of Observations & Nut & Kernel \\
\hline Moisture content (\% w.b.) & 60 & $19.83 \pm 3.71$ & $8.89 \pm 2.22$ \\
\hline Major diameter, $\mathrm{d}_{3}(\mathrm{~mm})$ & 300 & $14.16 \pm 0.79$ & $9.07 \pm 0.72$ \\
\hline Intermediate diameter, $\mathrm{d}_{2}(\mathrm{~mm})$ & 300 & $10.17 \pm 0.36$ & $7.32 \pm 0.49$ \\
\hline Minor diameter, $\mathrm{d}_{1}(\mathrm{~mm})$ & 300 & $9.78 \pm 0.28$ & $7.08 \pm 0.41$ \\
\hline Geometric mean diameter, GMD (mm) & 300 & $11.20 \pm 0.33$ & $7.77 \pm 0.36$ \\
\hline Sphericity $\%)$ & 300 & $79.27 \pm 3.07$ & $85.97 \pm 5.27$ \\
\hline Surface area $\left(\mathrm{mm}^{2}\right)$ & 300 & $394.75 \pm 23.13$ & $189.85 \pm 17.34$ \\
\hline Volume $\left(\mathrm{mm}{ }^{3}\right)$ & 300 & $738.37 \pm 64.96$ & $246.71 \pm 33.60$ \\
\hline Unit mass $(\mathrm{g})$ & 300 & $0.503 \pm 0.05$ & $0.328 \pm 0.03$ \\
\hline Density $\left(\mathrm{kg} / \mathrm{m}^{3}\right)$ & 300 & $681.1 \pm 20$ & $1342.1 \pm 136.23$ \\
\hline Bulk density $\left(\mathrm{kg} / \mathrm{m}^{3}\right)$ & 300 & $440.24 \pm 0.04$ & $773.06 \pm 0.06$ \\
\hline Porosity $(\%)$ & 300 & $36.65 \pm 0.74$ & $42.28 \pm 4.10$ \\
\hline
\end{tabular}

Note: The values of mean and standard deviation are designated as Mean \pm S.D. 


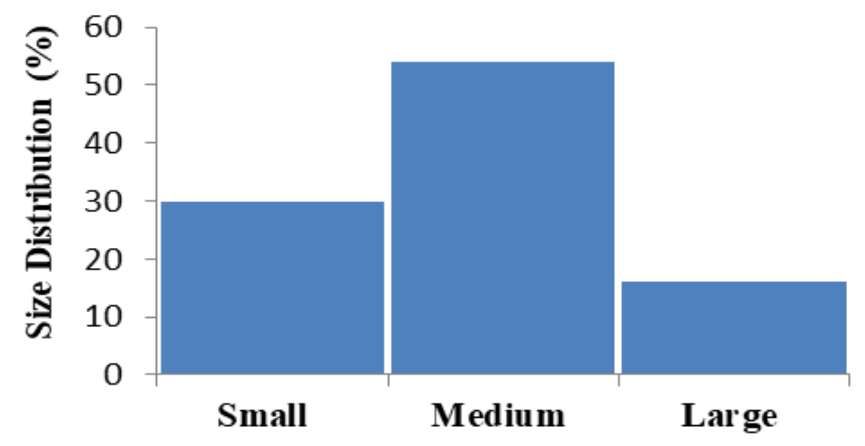

Size Ranges

Figure 2 Histogram showing the \% size distribution of kariya nuts.

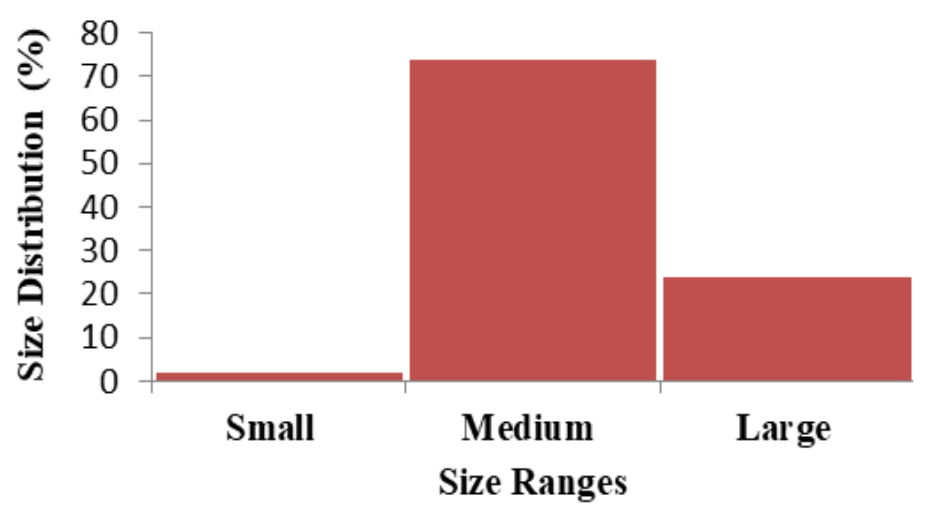

Figure 3 Histogram showing the \% size distribution of kariya kernels.

\subsection{Moisture Content of Kariya Nut and Kernel}

Moisture content of kariya nut and kernel were found to be $19.83 \pm 3.71 \%$ and $8.89 \pm 2.22 \%$ (w.b.), respectively. It was observed that the moisture content of kariya nut was greater than that of kernel. The shell fragment was discovered to behave like an elastic material when torn by hand. This might have been the reason it was able to harbour almost $50 \%$ of the nut moisture content.

\subsection{Size Distribution}

From Table 1 , the mean of values of major diameter $\left(d_{3}\right)$, intermediate diameter $\left(d_{2}\right)$, minor diameter $\left(d_{1}\right)$, and geometric mean diameter (GMD) for kariya nut and kernel were $14.16 \pm 0.79 \mathrm{~mm}, 10.17 \pm 0.36 \mathrm{~mm}, 9.78 \pm 0.28 \mathrm{~mm}$ and $11.20 \pm 0.33 \mathrm{~mm}$; and $9.07 \pm 0.72 \mathrm{~mm}, 7.32 \pm 0.49 \mathrm{~mm}, 7.08 \pm 0.41 \mathrm{~mm}$ and $7.77 \pm 0.36 \mathrm{~mm}$, respectively. The mean \% decrease of $d_{2}$ and $d_{1}$ with respect to $d_{3}$ were $28.20 \%$ and $30.93 \%$, respectively for the kariya nut while the corresponding values for kernel were $19.30 \%$ and $21.90 \%$, respectively. Hence, the mean values of $d_{2}$ and $d_{1}$ of the kernel were closed. This might be attributed to the fact that the kernel is spherical in shape. It was also found that the $\%$ nut and kernel sizes distribution based on GMD and the total sample used in the experiment were 30\% small, 54\% medium and 16\% large size ranges; and 2\% small, 74\% medium and 24\% large size ranges, respectively. The calculated skewness value for the nut size distribution was 0.08 (i.e. positive skewness). The observed value was almost closed to zero which indicates that the size distribution was relatively symmetrical. Besides, from Figure 2, the skewed distribution is towards the left side. This implies that the mean, mode and median of the data set were slightly different. Hence, greater portion of data was between the small and medium size ranges $(10.0 \mathrm{~mm} \leq \mathrm{GMD}<11.5 \mathrm{~mm})$. On the other hand, the calculated skewness value for the kernel size distribution was -0.24 (i.e. negative skewness). The observed value was also closed to zero. Figure 3 shows that the skewed distribution is towards the right side which still implies that the mean, mode and median of the data set were not the same. Hence, greater portion of data was between 
the medium and large size ranges $(7.0 \mathrm{~mm} \leq \mathrm{GMD}<9.0 \mathrm{~mm})$. Thus, the observed values of geometric mean diameter could be incorporated in the design of sorting and screening system for the cracked mixture or in cleaning systems.

\subsection{Sphericity and Shape of Kariya Nut and Kernel}

From Table 1, the mean of values of sphericity $(\psi)$ for kariya nut and kernel were $79.27 \pm 3.70 \%$ and $85.97 \pm 5.27 \%$, respectively. The sphericity values prove that the nuts and kernels are almost a sphere and can freely roll on any surface without resistance. This information could be used in the design of kariya nutcracker, separating system for cracked mixture of kernels / shell fragments and milling machine for kariya seeds.

\subsection{Surface Area of Kariya Nut and Kernel}

The mean surface area of kariya nut and kernel were found to be $394.75 \pm 23.13 \mathrm{~mm}^{2}$ and $189.85 \pm 17.34 \mathrm{~mm}^{2}$, respectively. The values obtained could be employed in the design heat and mass transfer equipment when considering the known surface area that would be exposed to heat treatment processes during oil extraction or transient heat process.

\subsection{Unit Mass of Kariya Nut and Kernel}

The mean unit mass of kariya nut and kernel were obtained as $0.503 \pm 0.05 \mathrm{~g}$ and $0.328 \pm 0.03 \mathrm{~g}$, respectively. It was observed that shell fragment was about $0.272 \pm 0.04 \mathrm{~g}$. The observed weight of shell fragment could suggest the pneumatic method of separating the cracked mixture. Unit mass could also be employed in the design of handling and weighing system for large scale kariya kernel processing.

\subsection{Volume and Density of Kariya Nut and Kernel}

The mean volume of kariya nut and kernel were found to be $738.37 \pm 64.96 \mathrm{~mm}^{3}$ and $246.71 \pm 33.60 \mathrm{~mm}^{3}$, respectively. Volume of the nut was found to be higher than that of kernel. The values of volume might be useful in screening solids and sorting systems. Mean values of density for the nut and kernel were $681.1 \pm 20 \mathrm{~kg} / \mathrm{m}^{3}$ and $1342.1 \pm 136.23 \mathrm{~kg} /$ $\mathrm{m}^{3}$, respectively. As observed, the nuts could not sinked in water which might be due to the void space between the shell and kernel. Hence, water displacement method of volume determination was not possible. The implication of density values is that the kernels would sink in water, which makes it possible to separate them from foreign materials while the nuts could float on water. The observed density values could assist in process calculation and product characterization.

\subsection{Bulk Density}

The mean values of kariya nut and kernel bulk density were $440.24 \pm 0.04 \mathrm{~kg} / \mathrm{m}^{3}$ and $773.60 \pm 0.06 \mathrm{~kg} / \mathrm{m}^{3}$, respectively. Kernel bulk density was higher than that of the nut. These values are useful in containerization, transportation and in the designing a suitable packaging or storage system e.g. silo, bins, etc.

\subsection{Porosity}

The mean values of kariya nut and kernel porosity were found to be $36.65 \pm 0.74 \%$ and $42.28 \pm 4.10 \%$, respectively. The implication is that the kernels would create more air-spaces (spores) among their particles than the nuts when stacked in a container. Hence, for the purpose of process calculation, it should be noted that spores inside the kernels are not included in the air volume; hence, the values are useful in storage system design.

\section{Conclusion}

In this study, some physical properties of kariya nut and kernel were investigated at the moisture content of $19.83 \pm$ $3.71 \%$ and $8.89 \pm 2.22 \%$, respectively. Data collected could assist in the rational design of kariya nut and kernel processing, and handling equipment for efficient unit operations.

\section{Compliance with ethical standards}

\section{Acknowledgments}

We appreciate the support and contributions of the course lecturers of FDE 715 (Advanced Physico-chemical and Engineering Properties of Foods and Ingredients), Department of Agricultural and Food Engineering, Faculty of Engineering, University of Uyo, Uyo. 


\section{Disclosure of conflict of interest}

There is no conflict of interest.

\section{References}

[1] Hildergadia Notes. Hildergadia. 2009.

[2] Inglett GE, Cavins JF, Spencer GF. Seed composition of Hildegardia barteri. Economy Botany. 1973; 27(1): 128130.

[3] Gopalan C, Ramma SBV, Balasubramanian SC. Nutritive Value of Indian Food. National Institute of Nutrition. Delhi. India Council of Medical Research Press. 2007.

[4] Akinoso R, Igbeka JC, Olayanju TMA, Bankole LK. Effects of Storage on the Quality of Palm Kernel and Sesame Oils. Proceedings 7th International Conference and 28th Annual General Meeting, November 6-10, 2006, Zaria, Nigeria. 2006.

[5] Burubai W, Akor A, Igoni A, Puyate Y. Some physical properties of nutmeg. International Agrophysics. 2007; 21 : 123-126.

[6] Alonge AF, Adegbulugbe TA. Some physical properties of groundnuts (Arachis hypogeal L). Journal of Agricultural Engineering and Technology (JAET). 2005; 13: 65-70.

[7] Alonge AF, Adetunji WB. Properties of coconut (Cocos nucifera l.) relevant to its dehusking. Journal of Agricultural Science and Technology A1. USA. Published by David Publishing. 2011; 1: 1089 - 1094.

[8] Alonge AF, Etim PJ. Some engineering properties of African oil bean relevant to its processing. Journal of Agricultural Engineering and Technology (JAET). 2011; 19(2): 51-5.

[9] Alonge AF, Folorunso AO. Some engineering properties of coconut relevant to its cracking. Paper presented at the Canadian Society for Bio Engineering (CSBE), Orillia, Toronto, Canada. July 15-18, 2012.

[10] Udoh JE, Olayanju TMA, Dairo OU, Alonge AF. Effect of moisture content on the mechanical and oil properties of soursop seeds. Chemical Engineering Transactions. 2017; 58: 367-372.

[11] Alonge AF, Ubak ED, Ikrang EG. Effect of moisture content on the physical properties of pumpkin. Proceedings of the XIX World Congress of the International Commission of Agricultural and Biosystems Engineering (CIGR) hold at Antalya, Turkey between April 22 and 25, 2018.

[12] Akubuo CO, Eje BE. Palm kernel and shell separator. Bio-system Engineering. 2002; 81(2): 193-199.

[13] Alonge AF. Some engineering properties of cashew nuts relevant to its processing. Proceedings of the 2nd International Conference on Engineering Research and Development (ICER\&D) held at the University of Benin, Benin City, Nigeria between 13th and 17th April 2008: 771-779.

[14] Rao M, Syed R, Ashim D. Engineering properties of foods (3rd edition). United States of America. CRC Press. 2005.

[15] Alonge AF, Ana IM, Abuajah CI. Some Physical properties of Chrysobalanus Atacorensis relevant to its processing. Journal of Agricultural Engineering and Technology (JAET). 2012; 20(2): 77- 82.

[16] Abuajah CI, Alonge AF. Physical properties of African kidney bean (Phaseolus vulgaris L.) and their processing impact. Food Biology. 2013; 2(2): 18-23.

[17] Alonge AF, Antia EO. Some physical and frictional properties of African bread fruit (Treculia Africana) seed relevant to its processing. Paper No. 1897372. St. Joseph, Michigan, USA: American Society of Agricultural and Biological Engineers. 2014.

[18] ASABE. ASABE Standard Year Book, American Society of Agricultural and Biological Engineers. 2010.

[19] Antia 00, Olosunde W, Offiong A. Determination of optimum moisture content of palm nut cracking for efficient production of whole kernel. Nigerian Journal of Technological Development. 2014; 11(2): 27-30.

[20] Alonge AF, Etim PJ. Effect of moisture content on some physical properties of mucuna bean seed. Acta Hort. (ISHS). 2017; 1152: 149-158.

[21] Irtwange SV, Igbeka JC. Some physical properties of two African yam bean (Sphenostylis stenocappa) accessions and their interrelations with moisture content. Applied Engineering in Agriculture. 2000; 18(5): 567-576. 
[22] Alonge FA, Edidiong JU. Some physical properties of African nutmeg (Monodara myristica) seed relevant to its processing. ASABE Annual International Meeting. 2012. Paper No. 121340755.

[23] Mohsenin NN. Physical properties of plant and animal materials. 2nd edition. New York. Gordon and Breach Science Publisher. 1987. 